\title{
Role of Hepatic Autoregulation in Defense against Hypoglycemia in Humans
}

\author{
G. Bolli, P. De Feo, G. Perriello, S. De Cosmo, M. Ventura, P. Campbell, P. Brunetti, and J. E. Gerich \\ Institute of Medical Pathology, University of Perugia, Perugia 06100, Italy; the Endocrine Research Unit, and Departments of \\ Medicine and Physiology, Mayo Medical School and Mayo Clinic, Rochester, Minnesota 55905
}

\begin{abstract}
To assess the role of hepatic autoregulation in defense against hypoglycemia, we compared the effects of complete blockade of glucose counterregulation with those of blockade of only neurohumoral counterregulation during moderate $(\sim 50 \mathrm{mg} / \mathrm{dl})$ and severe $(\sim 30 \mathrm{mg} / \mathrm{dl})$ hypoglycemia induced by physiologic hyperinsulinemia during subcutaneous infusion of insulin in normal volunteers. Compared with observations in control experiments, neurohumoral counterregulatory blockade (somatostatin, propranolol, phentolamine, and metyrapone), during which identical moderate hypoglycemia was achieved using the glucose clamp technique, resulted in suppressed glucose production $(0.62 \pm 0.08$ vs. $1.56 \pm 0.07 \mathrm{mg} / \mathrm{kg}$ per $\mathrm{min}$ at $12 \mathrm{~h}, P$ $<0.01)$ and augmented glucose utilization $(2.17 \pm 0.18$ vs. $1.57 \pm 0.07 \mathrm{mg} / \mathrm{kg}$ per min at $12 \mathrm{~h}, P<0.01)$. Complete blockade of counterregulation (neurohumoral blockade plus prevention of hypoglycemia) did not further enhance the suppressive effects of insulin on glucose production. However, when severe hypoglycemia was induced during neurohumoral counterregulatory blockade, glucose production was nearly two times greater $(1.05 \pm 0.05 \mathrm{mg} / \mathrm{kg}$ per $\mathrm{min}$ at $9 \mathrm{~h})$ than that observed during complete counterregulatory blockade $(0.58 \pm 0.08 \mathrm{mg} /$ kg per min at $9 \mathrm{~h}, P<0.01)$ and that observed during mere neurohumoral blockade with moderate hypoglycemia $(0.59 \pm 0.06$ $\mathrm{mg} / \mathrm{kg}$ per min at $9 \mathrm{~h}, P<0.01)$. These results demonstrate that glucose counterregulation involves both neurohumoral and hepatic autoregulatory components: neurohumoral factors, which require only moderate hypoglycemia for their activation, augment glucose production and reduce glucose utilization; hepatic autoregulation requires severe hypoglycemia for its activation and may thus serve as an emergency system to protect the brain when other counterregulatory factors fail to prevent threatening hypoglycemia.
\end{abstract}

\section{Introduction}

The ability of the liver to alter its output of glucose in response to changes in circulating glucose levels independent of neuronal and hormonal influences has been referred to as hepatic autoregulation (1). Nearly 50 yr ago Soskin and his colleagues (2) postulated that this was the main mechanism regulating hepatic glucose output and that hormones such as insulin merely modulated the sensitivity of the liver to glucose. Subsequently, both in vitro and in vivo studies (3-11) have provided considerable evidence that increases in glucose concentrations can directly suppress hepatic glucose output. How-

\footnotetext{
Address reprint requests to Dr. Bolli or Dr. Gerich.

Received for publication 28 September 1984 and in revised form 26 December 1984.
}

J. Clin. Invest.

(c) The American Society for Clinical Investigation, Inc. 0021-9738/85/05/1623/09 \$1.00

Volume 75, May 1985, 1623-1631 ever, it has not been firmly established whether decreases in glucose concentrations below normal values can directly augment hepatic glucose output. Consequently, the role of hepatic autoregulation in defense against hypoglycemia remains unclear (12-19)

For example, Sokal and Weintraub failed to observe an increase in glucose output from rat livers perfused in vitro when perfusate glucose concentrations were decreased (12), whereas others $(13,14)$ did find increases in glucose output when rat livers were perfused at low glucose concentrations. Moreover, as shown by Koerker and Halter (14), release of catecholamines rather than hepatic autoregulation could readily explain the increase in hepatic glucose production observed by Gerich et al. (10) during moderate hypoglycemia (50-70 $\mathrm{mg} / \mathrm{dl}$ ) in normal volunteers when circulating insulin and glucagon concentrations are maintained constant. Similarly, the increase in hepatic glucose production found by Saccà and his colleagues (15) during moderate hypoglycemia in normal volunteers before increases in circulating concentrations of counterregulatory hormones could have been due to activation of sympathetic impulses to the liver (16), suppression of endogenous insulin secretion, or merely to the effects of undetected changes in circulating counterregulatory hormones.

On the other hand, although Cryer and Gerich (17) and Gerich et al. (18) have concluded that hepatic autoregulation is not critical for recovery from hypoglycemia, their data do not exclude an important role for autoregulation in preventing the development of more severe hypoglycemia; furthermore, in the studies that largely form the basis for their conclusion, either glucose production was not measured (18) or a near doubling of glucose production was observed that could have been due to hepatic autoregulation since it occurred during combined adrenergic blockade and inhibition of glucagon and growth hormone secretion (19).

In view of the uncertainty regarding the role of hepatic autoregulation in hypoglycemic glucose counterregulation, the present studies were undertaken to examine this question under physiologically relevant conditions using subcutaneous infusion of insulin to produce physiologic hyperinsulinemia. We compared the effects of complete blockade of glucose counterregulation and the effects of mere neurohumoral counterregulatory blockade on hepatic glucose production during both moderate $(\sim 50 \mathrm{mg} / \mathrm{dl})$ and severe $(\sim 30 \mathrm{mg} / \mathrm{dl})$ hypoglycemia. Our results indicate that during hypoglycemia hepatic autoregulation is activated when plasma glucose levels decrease to the point at which cerebral function becomes impaired. Thus, under these conditions, hepatic autoregulation may act as a final counterregulatory safeguard in preventing hypoglycemic brain damage.

\section{Methods}

Subjects. Informed written consent was obtained from 12 normal volunteers (6 men and 6 women) aged $25 \pm 1 \mathrm{yr}$, who were within $10 \%$ of their ideal body weight (Metropolitan Life Insurance Co. tables, 
1959) and had no family history of diabetes mellitus. All subjects consumed a weight maintenance diet containing at least $250 \mathrm{~g}$ carbohydrate for $\mathbf{3 d}$ before study. Seven subjects (three men and four women) participated in control experiments. One of these and five additional subjects (four men and two women) all participated in the second, third, and fourth series of experiments (paired studies); three of the latter subjects (two men and one woman) participated in the last set of experiments, which assessed the adequacy of adrenergic blockade.

Protocol. All subjects were admitted to the Clinical Study Unit between 6:30 and 7:00 a.m., after fasting overnight (10-12 h); they were placed at bedrest and maintained in the supine position throughout experiments. To obtain arterialized venous blood samples, a hand vein was cannulated in retrograde fashion with a 21 -gauge butterfly needle and maintained at $65^{\circ} \mathrm{C}$ in a thermoregulated glass box. An antecubital vein of the contralateral arm was cannulated with an 18-gauge catheter and was used for primed $(11 \mu \mathrm{Ci})$ continuous $(0.11 \mu \mathrm{Ci} / \mathrm{min})$ infusion of 3-[3 $\mathrm{H}]$ glucose (New England Nuclear, Boston, MA) for isotopic determination of glucose production and glucose use. $3 \mathrm{~h}$ were allowed for isotopic equilibration, after which baseline blood samples were taken.

Five sets of experiments were performed. In the first set (control experiments), insulin (Actrapid MC U-40; Novo Research Institute, Copenhagen, Denmark) diluted to $\sim 15 \mathrm{U} / \mathrm{ml}$ in $0.9 \% \mathrm{NaCl}$ containing $0.5 \%$ human albumin (Immuno S.P.A., Pisa, Italy) was infused subcutaneously through a 25 -gauge butterfly needle placed $2 \mathrm{~cm}$ to the right or left of the umbilicus at a rate of $15 \mathrm{mU} / \mathrm{M}^{2}$ per min for $12 \mathrm{~h}$ using a pump (Harvard Apparatus Co., Inc., The Ealing Corp., S. Natick, MA). This route of insulin administration was chosen to simulate the type of hypoglycemia that might develop in diabetic patients being treated with continuous subcutaneous insulin infusion.

In the second set of experiments, to assess the effects of inhibition of neurohumoral counterregulation, the endogenous secretion of counterregulatory hormones (or their actions) was blocked, and in the cases of glucagon, growth hormone, and cortisol, circulating levels were maintained at fixed basal values using replacement hormone infusions. Since inhibition of glucagon and growth hormone secretion required the use of somatostatin, which also inhibited insulin release, it was necessary to infuse insulin initially intravenously to maintain euglycemia. Secretion of glucagon and growth hormone was suppressed by infusion of somatostatin (Serono S.P.A., Rome, Italy; $500 \mu \mathrm{g} / \mathrm{h}$ from $-3 \mathrm{~h}$ ); secretion of cortisol was suppressed by administration of metyrapone (kindly provided by Ciba-Geigy, Origgio, Varese, Italy; $500 \mathrm{mg}$ every $4 \mathrm{~h}$ from $-3 \mathrm{~h}$ ); and adrenergic effects of epinephrine and norepinephrine were prevented by infusion of alpha and beta adrenergic receptor antagonists (phentolamine, Ciba-Geigy, $0.5 \mathrm{mg} / \mathrm{min}$; and propranolol, Imperial Chemical Industries, Caponago, Milan, Italy, $0.1 \mathrm{mg} / \mathrm{min}$ from $-3 \mathrm{~h}$ ). Circulating levels of glucagon (Novo Research Institute), cortisol (Richter S.P.A., Milan, Italy), and growth hormone (Kabi [AB], Stockholm, Sweden) were maintained at basal concentrations by replacement infusions of these harmones $(0.65 \mathrm{ng} / \mathrm{kg}$ per $\min , 0.3 \mu \mathrm{g} /$ $\mathrm{kg}$ per $\mathrm{min}$, and $3 \mathrm{ng} / \mathrm{kg}$ per min, respectively). All reagents were prepared the morning of experiments and were infused by separate pumps (Harvard Apparatus Co., Inc., The Ealing Corp.) in $0.9 \% \mathrm{NaCl}$ containing $0.5 \%$ human serum albumin. Euglycemia was maintained during the somatostatin-induced suppression of endogenous insulin secretion by a feedback intravenous infusion of insulin as previously described (20). After initiation of the subcutaneous insulin infusion (15 $\mathrm{mU} / \mathrm{M}^{2}$ per min), intravenous infusion of insulin was tapered to mimic suppression of endogenous insulin secretion in control experiments (i.e., $80 \%$ of basal from $30-60 \mathrm{~min}, 50 \%$ of basal from $60-120$ min, $30 \%$ of basal from $120-280 \mathrm{~min}$, and $10 \%$ from $180-240 \mathrm{~min}$ ). Glucose was infused by a separate pump (Harvard Apparatus Co., Inc., The Ealing Corp.) at a variable rate to reproduce as closely as possible the plasma glucose concentrations observed in the control experiments, thus eliminating differences in hypoglycemia as an experimental variable.
In the third set of experiments, neurohumoral counterregulation as well as the potential contribution of hepatic autoregulation were inhibited; experiments were conducted in a manner identical to the second set of experiments, except that sufficient glucose was infused to "clamp" plasma glucose concentrations at basal levels and prevent hypoglycemic activation of counterregulation.

In the fourth set of experiments, the potential contribution of hepatic autoregulation during hypoglycemia more severe than that produced in the first and second sets of experiments was evaluated. The experiments were conducted in a manner identical to the second set of experiments except that less glucose was infused to permit plasma glucose concentrations to decrease to nearly $30 \mathrm{mg} / \mathrm{dl}$. Because prolongation of this degree of hypoglycemia did not seem ethically justifiable, these experiments were terminated $3 \mathrm{~h}$ earlier than the others.

During performance of the above experiments, subjects were under constant EKG monitoring and two physicians, one of whom was a cardiologist, were always present. The subjects' plasma glucose concentrations (every $5 \mathrm{~min}$ ), blood pressure (every 10-15 $\mathrm{min}$ ), state of consciousness, and willingness to continue the experiments were frequently assessed. During the studies involving severe hypoglycemia, all six subjects experienced sweating; five had headaches; four felt nauseated; three became drowsy; and two noted slowing of their heart rate. None vomited or lost consciousness. Heart rate decreased from $74 \pm 2$ to $47 \pm 1$ beats/min, and blood pressure decreased from 122 \pm 4 / $86 \pm 2$ to $105 \pm 1 / 65 \pm 3 \mathrm{mmHg}$. Four of the six subjects indicated that they would be willing to undergo the experiments again.

In considering the safety of these experiments, we felt that the main potential risks would be cardiac arrhythmia due to activation of the autonomic nervous system and neuronal damage due to neuroglycopenia. With respect to the first risk, cardiac tachyarrhythmia due to excessive sympathoadrenal activity seemed unlikely to occur since blockade of the sympathoadrenal system was an intrinsic part of the protocol. As far as severe bradycardia was concerned, we felt this could be rapidly reversed with atropine if it occurred. Finally, regarding the potential neuronal damage caused by neuroglycopenia, previous studies in which plasma glucose levels were clamped at $\sim 40 \mathrm{mg} / \mathrm{dl}$ for $4 \mathrm{~h}$ in normal human volunteers had indicated no adverse effects (21). Moreover, studies by Aver et al. in rats (22) and Cohen et al. (23) and Theilgaard et al. (24) in humans indicated no residual neurologic impairment was likely to occur at the plasma glucose levels intended for study. Finally, it had been decided beforehand to immediately abort experiments with an intravenous injection of glucose if subjects could no longer respond appropriately to questions. Although this did not become necessary, we felt that the decision to terminate experiments at such a point would minimize risks. These studies were reviewed and approved by the Mayo Institutional Review Board, Rochester, $\mathrm{MN}$.

In the final set of experiments, to assess whether infusion of the adrenergic receptor antagonists had been sufficient to block adrenergic effects on hepatic glucose output, three subjects were infused with phentolamine and propranolol at rates used in the previous experiments for $2 \mathrm{~h}$. After the first hour, epinephrine $(5 \mu \mathrm{g} / \mathrm{min}$; Angelini S.P.A., Rome, Italy) and norepinephrine ( $2.5 \mu \mathrm{g} / \mathrm{min}$; Winthrop S.P.A., Milan, Italy), made up in $0.9 \% \mathrm{NaCl}$ containing ascorbic acid $(0.5 \mathrm{mg} / \mathrm{ml})$, were infused at rates estimated $(25,26)$ to raise the circulating concentrations of these catecholamines above those levels observed in the preceding experiments.

Analyses. Blood samples were collected at 15-30 min intervals and assayed for glucose (glucose analyzer; Yellow Springs Instrument Co., Yellow Springs, OH), glucose specific activity (19), insulin (27), Cpeptide (28), glucagon (29), cortisol (30), growth hormone (31), epinephrine (32), norepinephrine (32), and FFA (33) by previously described methods. Rates of glucose appearance (production) and disappearance (utilization) were calculated using the non-steady state equations of De Bodo et al. (34). Rates of exogenously infused glucose were subtracted from rates of total glucose appearance to yield estimates 
of endogenous glucose production (35). Data in text and figures are given as mean \pm SEM, and their statistical significance was evaluated using analysis of variance corrected for repeated measures and twotailed unpaired (and where appropriate, paired) $t$ test (36).

\section{Results}

\section{Effect of inhibition of neurohumoral counterregulation}

Plasma insulin and C-peptide concentrations (Fig. 1). In experiments in which neurohumoral counterregulation was to be prevented, insulin was infused intravenously before subcutaneous infusion of insulin to maintain euglycemia during inhibition of insulin secretion by somatostatin; basal plasma insulin levels $(16 \pm 1 \mu \mathrm{U} / \mathrm{ml})$ were greater and basal plasma $C$ peptide levels $(0.16 \pm 0.02 \mathrm{ng} / \mathrm{ml})$ were less than corresponding determinations in control experiments $(10 \pm 0.5 \mu \mathrm{U} / \mathrm{ml}$ and $1.2 \pm 0.06 \mathrm{ng} / \mathrm{ml}$, respectively, both $P<0.01$ ). However, after initiation of subcutaneous infusion of insulin, plasma insulin increased to comparable plateaus (26-28 $\mu \mathrm{U} / \mathrm{ml})$, and plasma C-peptide decreased to nearly undetectable levels $(>0.1 \mathrm{ng} /$ $\mathrm{ml}$ ) in both experiments.

Plasma glucose concentrations (Fig. 1). In control experiments, plasma glucose decreased progressively from $88 \pm 3 \mathrm{mg} /$ dl to $52 \pm 3 \mathrm{mg} / \mathrm{dl}$ at $9 \frac{1}{2} \mathrm{~h}$ and remained constant thereafter. In experiments in which neurohumoral counterregulation was prevented, this pattern was mimicked using infusion of glucose so that at no time was there a significant difference in plasma glucose concentrations between the two experiments.

Rates of glucose production and utilization (Fig. 1). In control experiments, glucose production decreased transiently
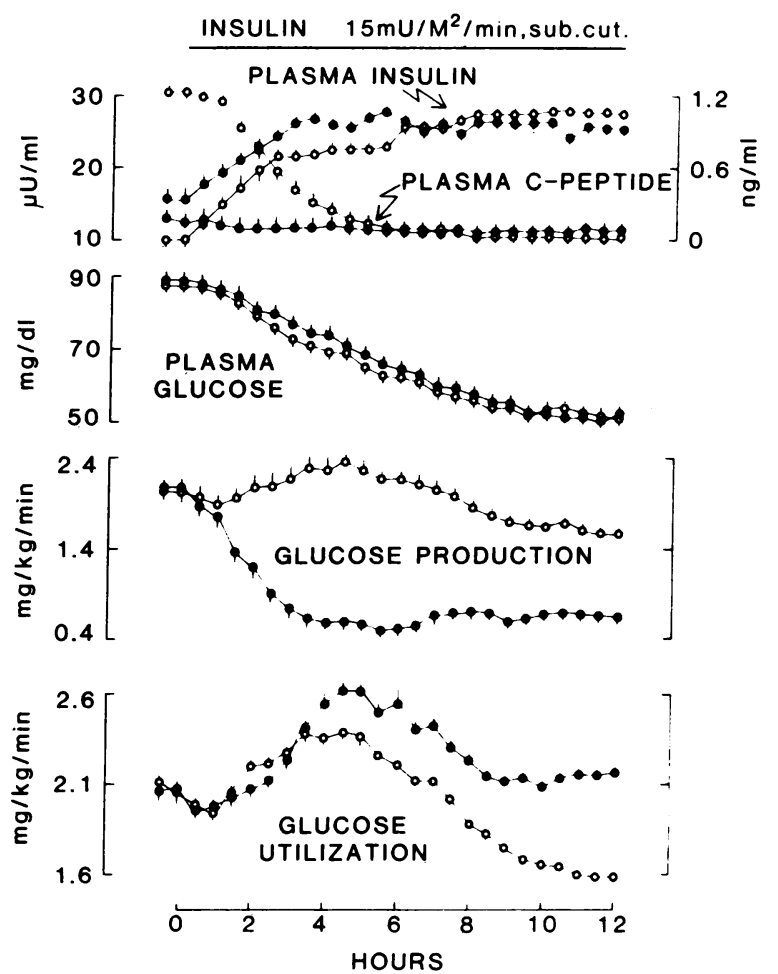

Figure 1. Plasma insulin, C-peptide, and glucose concentrations, and rates of glucose production and utilization during control experiments $(0, n=7)$ and during blockade of neurohumoral counterregulation $(\bullet, n=6)$. Mean \pm SEM. Sub. cut., subcutaneously. from $2.12 \pm 0.07$ to $1.89 \pm 0.05 \mathrm{mg} / \mathrm{kg}$ per min after $1 \mathrm{~h}$ and then increased to a peak value of $2.37 \pm 0.22 \mathrm{mg} / \mathrm{kg}$ per min at $4 \frac{1}{2} \mathrm{~h}$ before returning to basal rates by $6 \frac{1}{2} \mathrm{~h}$. In contrast, in experiments in which neurohumoral counterregulation was prevented, glucose production decreased progressively to a nadir of $0.48 \pm 0.1 \mathrm{mg} / \mathrm{kg}$ per min at $51 / 2 \mathrm{~h}$, and at $12 \mathrm{~h}$ was only $0.62 \pm 0.08 \mathrm{mg} / \mathrm{kg}$ per $\min (P<0.001$ vs. control $)$.

In both experiments, glucose utilization increased initially during subcutaneous infusion of insulin. However, despite virtually identical plasma glucose concentrations, glucose utilization in control experiments decreased below basal values by $8 \mathrm{~h}$, whereas in experiments in which neurohumoral counterregulation was prevented, glucose utilization remained at or above basal values throughout $(2.17 \pm 0.18$ vs. $1.57 \pm 0.07$ $\mathrm{mg} / \mathrm{kg}$ per min in control experiments at $12 \mathrm{~h}, P<0.01$ ). Thus, lack of neurohumoral counterregulation prevented increases in glucose production as well as decreases in glucose utilization in response to hypoglycemia.

Plasma counterregulatory factor concentrations (Fig. 2). In control experiments, plasma concentrations of glucagon, norepinephrine, epinephrine, growth hormone, and cortisol all increased significantly in response to hypoglycemia. In experiments in which neurohumoral counterregulation was prevented, plasma glucagon, growth hormone, and cortisol remained at their basal concentrations throughout; as expected, plasma norepinephrine and epinephrine increased to a greater degree than in control studies, since alpha and beta adrenergic receptor antagonists are known to impair neuronal catecholamine reuptake (37) and to decrease catecholamine clearance (38).

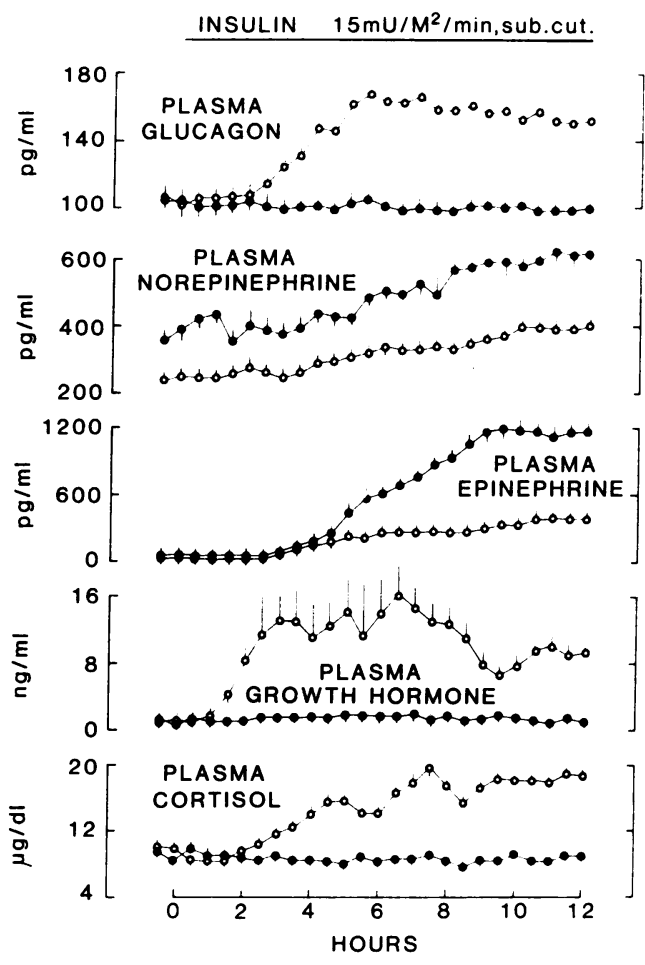

Figure 2. Plasma glucagon, norepinephrine, epinephrine, growth hormone, and cortisol concentrations during control experiments $(0, n$ $=7)$ and during blockade of neurohumoral counterregulation $(\bullet, n$ =6). Mean \pm SEM. Sub. cut., subcutaneously. 
Comparison of effects of complete inhibition of counterregulation and mere inhibition of neurohumoral counterregulation during moderate hypoglycemia

Plasma insulin and C-peptide concentrations (Fig. 3). Plasma insulin increased from comparable basal values $(15 \pm 1$ and $16 \pm 1 \mu \mathrm{U} / \mathrm{ml}$ ) during subcutaneous infusion of insulin to similar plateau levels $(\sim 26 \mu \mathrm{U} / \mathrm{ml})$, and plasma C-peptide was suppressed throughout to near undetectable levels in both experiments.

Plasma glucose concentrations (Fig. 3). In experiments in which complete inhibition of counterregulation (hepatic autoregulatory plus neurohumoral components) was attempted, plasma glucose concentrations were maintained at $88 \pm 1 \mathrm{mg} /$ dl during subcutaneous infusion of insulin using the glucoseclamp technique which prevented activation of counterregulatory systems by hypoglycemia. In experiments in which inhibition of only neurohumoral counterregulation was attempted, plasma glucose concentrations were allowed to decrease to $\sim 50 \mathrm{mg} / \mathrm{dl}$.

Rate of glucose production and utilization (Fig. 3). The pattern and absolute rates of glucose production were virtually identical during complete inhibition of counterregulation and mere inhibition of neurohumoral counterregulation. However, presumably because euglycemia had been maintained, rates of glucose utilization were significantly greater after $5 \mathrm{~h}$ in the experiments in which complete inhibition of counterregulation was attempted.

Plasma counterregulatory factor concentrations (Fig. 4). In experiments in which complete inhibition of counterregulation was attempted, circulating levels of all counterregulatory factors

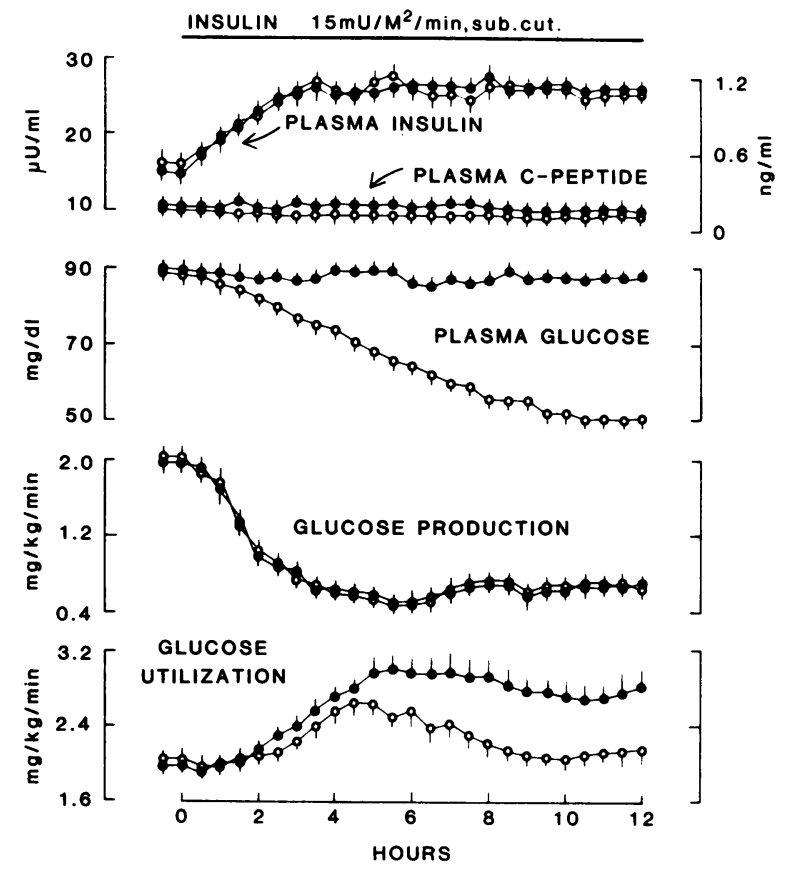

Figure 3. Plasma insulin, C-peptide, and glucose concentrations, and rates of glucose production and utilization during complete blockade of counterregulation ( $\bullet$ ) and during mere blockade of neurohumoral counterregulation (o) during moderate hypoglycemia. $n=6$. Mean \pm SEM. Sub. cut., subcutaneously.

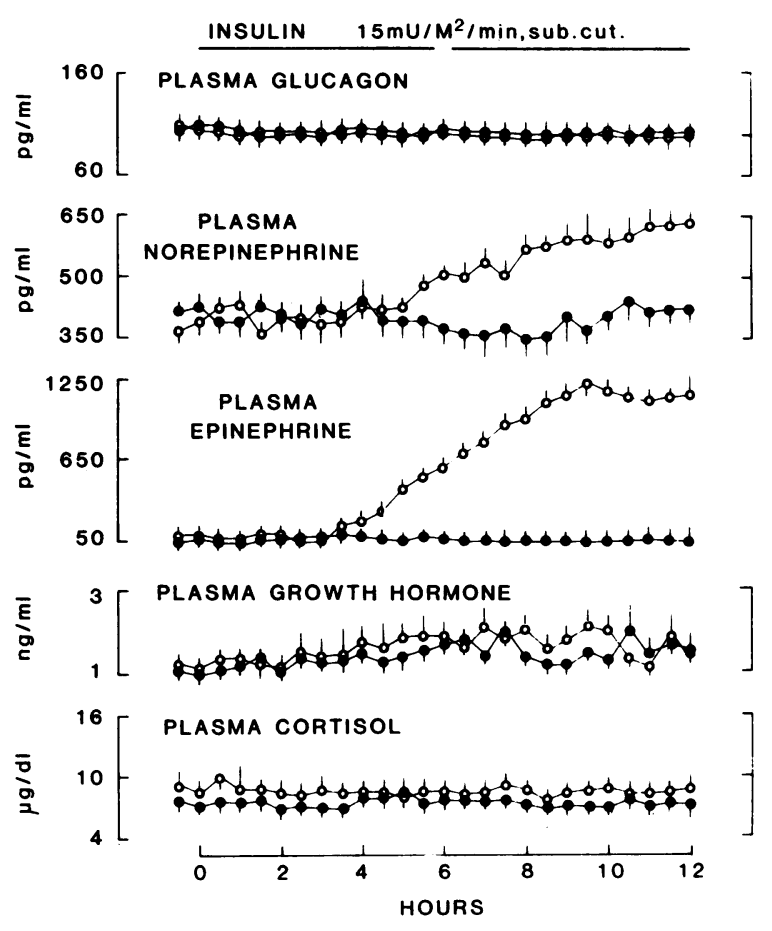

Figure 4. Plasma glucagon, norepinephrine, epinephrine, growth hormone, and cortisol concentrations during complete blockade of counterregulation ( $\bullet$ ) and during mere blockade of neurohumoral counterregulation (o) during moderate hypoglycemia. $n=6$. Mean \pm SEM. Sub. cut., subcutaneously.

remained at baseline values. As already described, in experiments in which mere inhibition of neurohumoral counterregulation was attempted, only plasma epinephrine and norepinephrine increased significantly.

\section{Comparison of effects of mere inhibition of neurohumoral counterregulation during moderate and severe hypoglycemia}

Plasma insulin and C-peptide concentrations (Fig. 5). Plasma insulin increased from comparable basal values $(15 \pm 1$ and $16 \pm 1 \mu \mathrm{U} / \mathrm{ml}$ ) during subcutaneous infusion of insulin to similar plateaus $(\sim 26 \mu \mathrm{U} / \mathrm{ml})$, and plasma C-peptide was suppressed throughout to near undetectable levels in both experiments.

Plasma glucose concentrations (Fig. 5). Basal plasma glucose concentrations were comparable in both sets of experiments $(86 \pm 2$ vs. $88 \pm 3 \mathrm{mg} / \mathrm{dl})$. By varying the infusion rate of exogenous glucose, in one set of experiments plasma glucose was allowed to decrease gradually ( $\sim 4 \mathrm{mg} / \mathrm{dl}$ per h) to $52 \pm 1$ $\mathrm{mg} / \mathrm{dl}$ after $9 \frac{1}{2} \mathrm{~h}$ and was subsequently maintained at that level; in the other set of experiments, plasma glucose was allowed to decrease more rapidly $(\sim 10 \mathrm{mg} / \mathrm{dl}$ per $\mathrm{h})$ to $32 \pm 1$ $\mathrm{mg} / \mathrm{dl}$ after $5 \mathrm{~h}(P<0.01)$ and was maintained at that level for the subsequent $4 \mathrm{~h}$.

Rates of glucose production and utilization (Fig. 5). Glucose production decreased from comparable baseline values to nearly identical values at $3 \mathrm{~h}(0.75 \pm 0.03$ [plasma glucose $52 \pm 2$ $\mathrm{mg} / \mathrm{dl}$ ] vs. $0.74 \pm 0.11$ [plasma glucose $77 \pm 1 \mathrm{mg} / \mathrm{dl}$ ] $\mathrm{mg} / \mathrm{kg}$ per $\mathrm{min}$ ); however, glucose production subsequently increased in the experiments with severe hypoglycemia, whereas in the 


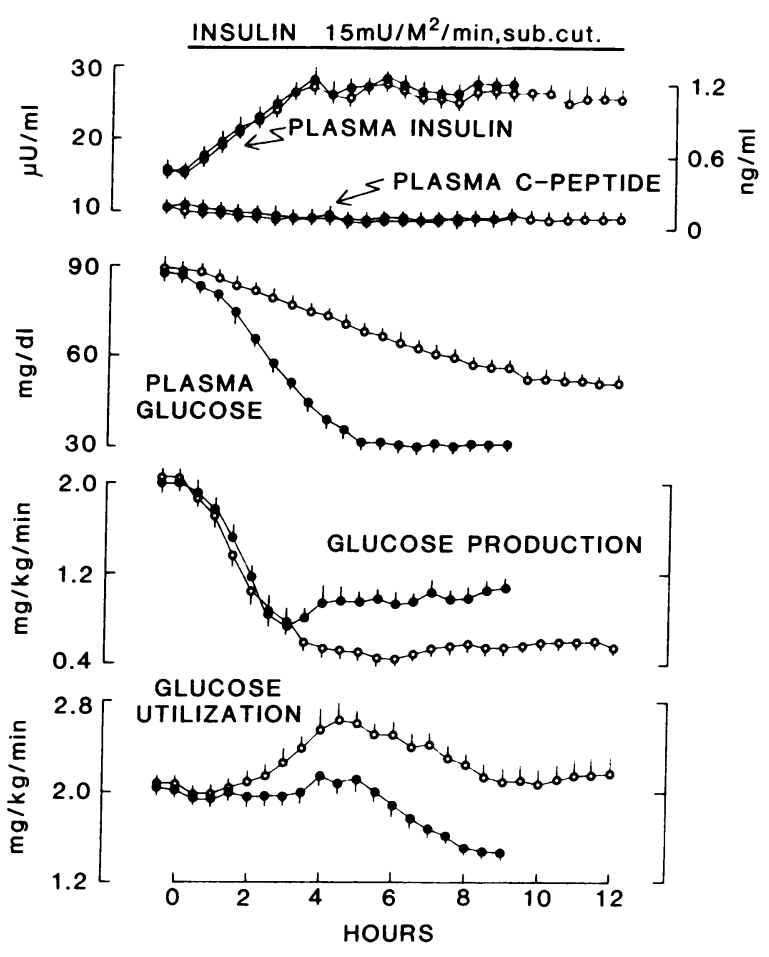

Figure 5. Plasma insulin, C-peptide, and glucose concentrations, and rates of glucose production and utilization during neurohumoral blockade of counterregulation (moderate [0] versus severe [•] hypoglycemia). $n=6$. Mean \pm SEM. Sub. cut., subcutaneously.

experiments with moderate hypoglycemia, it continued to decrease. Consequently, during the subsequent $4 \mathrm{~h}$, glucose production was more than $1 \frac{1}{2}$ times greater $(0.96 \pm 0.2$ vs. $0.61 \pm 0.02 \mathrm{mg} / \mathrm{kg}$ per $\mathrm{min}, P<0.01)$ in the experiments with severe hypoglycemia, and by the end of the experiment had increased to $\sim 60 \%$ of the rates observed in control experiments $(1.05 \pm 0.05$ vs. $1.70 \pm 0.10 \mathrm{mg} / \mathrm{kg}$ per $\mathrm{min}$ ) and was nearly twice as great as rates observed during complete counterregulatory blockade $(0.58 \pm 0.08 \mathrm{mg} / \mathrm{kg}$ per $\min , P<0.01)$ and during mere neurohumoral blockade associated with moderate hypoglycemia $(0.59 \pm 0.06 \mathrm{mg} / \mathrm{kg}$ per $\min , P<0.01)$.

Glucose utilization rates were consistently less in the experiments with severe hypoglycemia than those in experiments with moderate hypoglycemia beginning $\sim 2 \mathrm{~h}$ after the start of subcutaneous infusion of insulin due to plasma glucose concentrations in the two experiments becoming appreciably different.

Plasma counterregulatory factor concentrations (Fig. 6). In both sets of experiments, plasma glucagon, cortisol, and growth hormone remained at basal levels. Plasma norepinephrine and epinephrine increased to a greater degree in the experiments with severe hypoglycemia $(929 \pm 69$ and $187 \pm 96 \mathrm{pg} / \mathrm{ml}$ vs. $580 \pm 38$ and $1,122 \pm 75 \mathrm{pg} / \mathrm{ml}$, respectively, at $9 \mathrm{~h}$, both $P$ $<0.01)$.

Effects of complete inhibition of counterregulation and mere inhibition of neurohumoral counterregulation on plasma FFA concentrations (Table I)

In control experiments, plasma FFA decreased $50 \%$ to a nadir of $339 \pm 63 \mu \mathrm{M}$ at $3 \mathrm{~h}$ and then increased progressively above

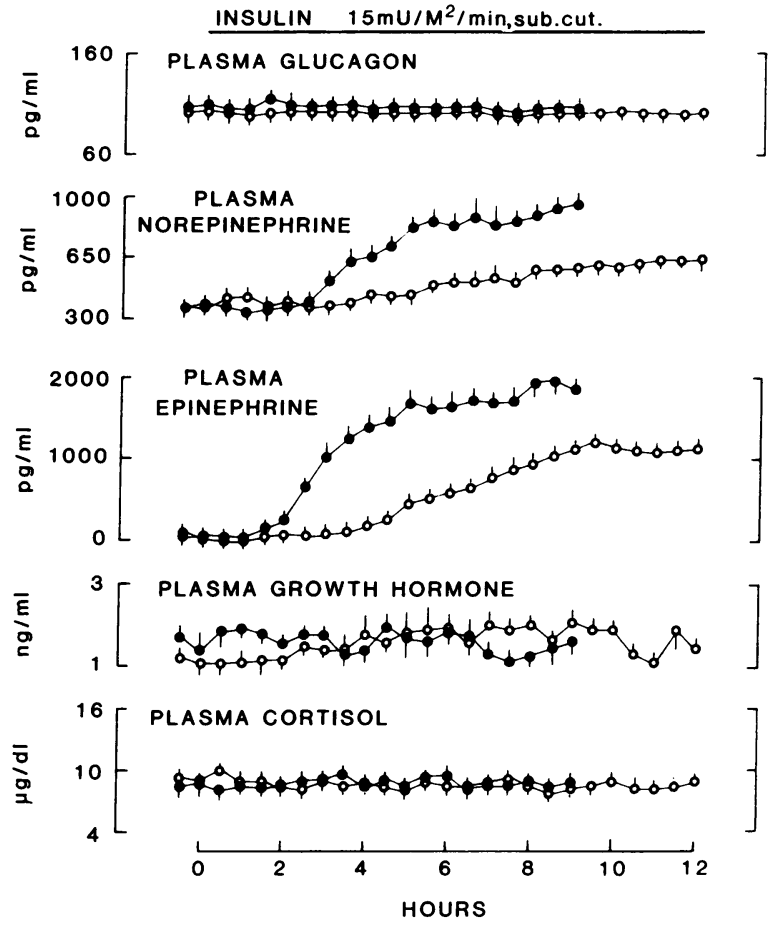

Figure 6. Plasma glucagon, norepinephrine, epinephrine, growth hormone, and cortisol concentrations during neurohumoral blockade of counterregulation (moderate [o] versus severe [๑] hypoglycemia). $n=6$. Mean \pm SEM. Sub. cut., subcutaneously.

basal values $(718 \pm 75 \mu \mathrm{M})$ to $1,089 \pm 81 \mu \mathrm{M}$ at $12 \mathrm{~h}, P<0.01$. During complete inhibition of counterregulation, plasma FFA were already significantly lower at $0 \mathrm{~min}(418 \pm 27 \mu \mathrm{M})$ than in control experiments $(P<0.01)$, presumably because of ongoing adrenergic blockade during infusion of insulin; they also decreased $50 \%$ by $3 \mathrm{~h}$ but did not subsequently increase. During mere inhibition of neurohumoral counterregulation, plasma FFA decreased $\sim 50 \%$ by $3 \mathrm{~h}$ during infusion of insulin and did not subsequently increase. Values during moderate and severe hypoglycemia were not significantly different from one another and were also not significantly different from values observed during complete inhibition of counterregulation.

Assessment of adequacy of adrenergic blockade (Fig. 7). Since plasma catecholamines increased to varying degrees in the preceding experiments, it was essential, for appropriate interpretation of the results of these experiments, to determine whether the alpha and beta adrenergic receptor antagonists had been administered in sufficient doses to block the effects of catecholamines on glucose production. Therefore, during infusion of the adrenergic receptor antagonists at rates used in the preceding experiments, norepinephrine and epinephrine were infused at rates calculated to produce circulating levels of these catecholamines that matched or exceeded the greatest levels seen in the preceding experiments. As shown in Fig. 7, plasma epinephrine increased to $1,928 \pm 141 \mathrm{pg} / \mathrm{ml}$ after $1 \mathrm{~h}$ compared with peak values of $1,934 \pm 107 \mathrm{pg} / \mathrm{ml}$ observed in preceding experiments (during neurohumoral blockade with severe hypoglycemia); plasma norepinephrine increased after $1 \mathrm{~h}$ to $1,085 \pm 117 \mathrm{pg} / \mathrm{ml}$ compared with peak values of $929 \pm 69$ 
Table I. Plasma FFA Concentrations*

\begin{tabular}{|c|c|c|c|c|c|c|c|c|c|c|c|c|c|}
\hline & \multicolumn{13}{|l|}{ Hours } \\
\hline & 0 & 1 & 2 & 3 & 4 & 5 & 6 & 7 & 8 & 9 & 10 & 11 & 12 \\
\hline \multicolumn{14}{|l|}{$\begin{array}{l}\text { Control } \\
\text { experiments }\end{array}$} \\
\hline$(n=7)$ & $718 \pm 75$ & $604 \pm 58$ & $431 \pm 50$ & $339 \pm 63$ & $413 \pm 51$ & $483 \pm 71$ & $693 \pm 94$ & $831 \pm 99$ & $888 \pm 83$ & $886 \pm 39$ & $984 \pm 65$ & $1,017 \pm 50$ & $1,089 \pm 81$ \\
\hline \multicolumn{14}{|l|}{$\begin{array}{l}\text { Complete } \\
\text { blockade }\end{array}$} \\
\hline$(n=6)$ & $418 \pm 27$ & $342 \pm 23$ & $279 \pm 20$ & $223 \pm 14$ & $199 \pm 9$ & $214 \pm 9$ & $220 \pm 7$ & $231 \pm 9$ & $245 \pm 7$ & $248 \pm 8$ & $251 \pm 7$ & $235 \pm 8$ & $247 \pm 3$ \\
\hline \multicolumn{14}{|l|}{$\begin{array}{c}\text { Neurohumoral } \\
\text { blockade } \\
\text { Moderate }\end{array}$} \\
\hline$(n=6)$ & $450 \pm 34$ & $403 \pm 32$ & $320 \pm 19$ & $256 \pm 11$ & $206 \pm 9$ & $219 \pm 8$ & $213 \pm 12$ & $256 \pm 12$ & $278 \pm 13$ & $257 \pm 9$ & $260 \pm 9$ & $256 \pm 7$ & $261 \pm 11$ \\
\hline \multicolumn{14}{|l|}{$\begin{array}{l}\text { Severe } \\
\text { hypoglycemia }\end{array}$} \\
\hline$(n=6)$ & $385 \pm 28$ & $259 \pm 13$ & $240 \pm 13$ & $209 \pm 9$ & $207 \pm 8$ & $223 \pm 8$ & $217 \pm 9$ & $221 \pm 9$ & $234 \pm 15$ & $242 \pm 10$ & - & - & - \\
\hline
\end{tabular}

*Concentrations given in micromolars.

$\mathrm{pg} / \mathrm{ml}$ observed in preceding experiments (during neurohumoral blockade with severe hypoglycemia). Despite these increases in plasma catecholamines, neither plasma glucose nor glucose production increased.

\section{Discussion}

These studies reaffirm the important role of neurohumoral factors in glucose counterregulation and provide evidence that during hypoglycemia hepatic glucose production can increase in the absence of neurohumoral influences, consistent with a role for hepatic autoregulation in defense against hypoglycemia in normal humans.

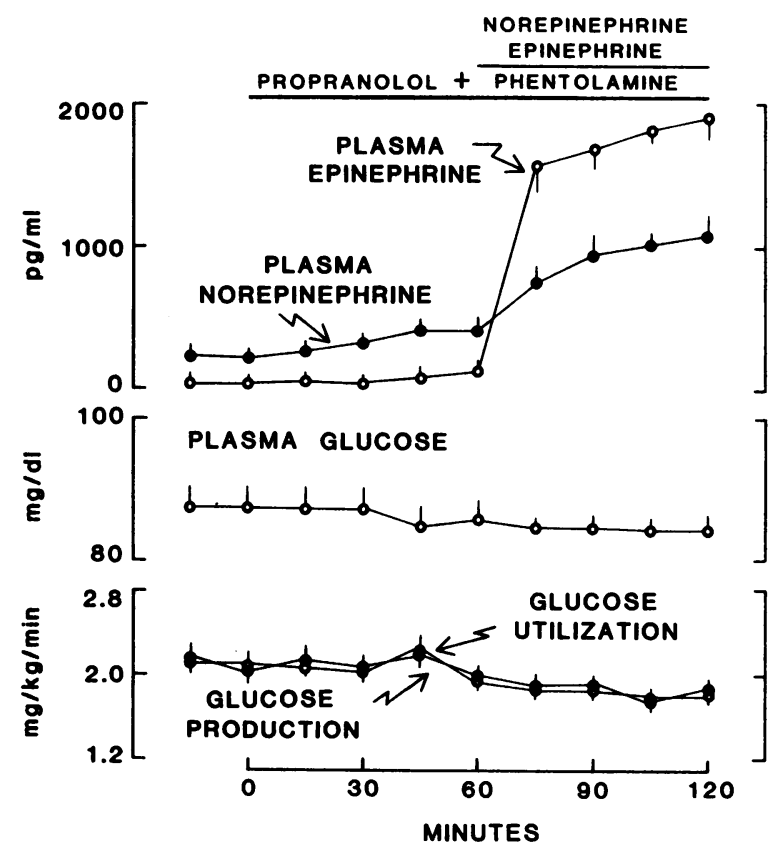

Figure 7. Effect of infusions of epinephrine and norepinephrine on plasma glucose concentrations and rates of glucose production and utilization during combined alpha and beta adrenergic blockade. $n=3$. Mean \pm SEM
Our first series of experiments was designed to permit evaluation of the effects of blockade of neurohumoral counterregulation on glucose production and utilization without differences in plasma glucose concentrations being an experimental variable. During hypoglycemia virtually identical to that observed in control experiments, blockade of neurohumoral counter-regulation (prevention of increases. in glucagon, growth hormone, and cortisol secretion in conjunction with blockade of alpha and beta adrenergic responses to secreted norepinephrine and epinephrine) resulted in complete inhibition of compensatory increases in glucose production and greater rates of glucose utilization than those observed in control experiments.

These observations thus indicate that neurohumoral counterregulation involves alterations in both glucose production and glucose utilization. Primarily as a result of short-term studies, it is currently thought that glucose counterregulation is predominantly or exclusively mediated through changes in glucose production, and that glucagon is the major glucose counterregulatory factor $(39,40)$. However, since glucagon affects only glucose production, our results indicate that during protracted hypoglycemia, other neurohumoral factors that affect glucose utilization are also important. Cortisol $(41,42)$, growth hormone $(43,44)$, epinephrine $(42,45,46)$, and norepinephrine (46), when administered in amounts producing circulating levels observed during hypoglycemia, have all been shown to impair glucose utilization. Growth hormone and cortisol generally require several hours to exert their effects $(47,48)$. Nevertheless, given the duration of hypoglycemia in the present studies, suppression of growth hormone, and cortisol secretion as well as blockade of the actions of epinephrine and norepinephrine could all have contributed to the enhanced glucose utilization observed during prevention of neurohumoral counterregulation. Additional studies will be necessary to delineate the individual contributions of each of these factors.

In this study, when glucose counterregulation during infusion of insulin was completely inhibited by prevention of hypoglycemia in addition to pharmacologic blockade of neurohumoral counterregulation, rates of glucose production were virtually identical to those observed during moderate hypoglycemia $(\sim 50 \mathrm{mg} / \mathrm{dl})$ when only neurohumoral components of 
glucose counterregulation were inhibited. Thus, these experiments failed to demonstrate a contribution of hepatic autoregulation. However, when more severe hypoglycemia $(\sim 30 \mathrm{mg} /$ dl) was allowed to develop during inhibition of neurohumoral counterregulation, rates of glucose production were nearly two times greater than those observed during complete inhibition of glucose counterregulation. These observations suggest that during hypoglycemia, hepatic glucose production can increase in the absence of neurohumoral influences and, thus, also provide evidence for participation of hepatic autoregulation in glucose counterregulation.

These conclusions assume that neurohumoral blockade was not overcome. Although plasma growth hormone and cortisol levels remained at basal concentrations during the severe hypoglycemia, plasma catecholamines were markedly increased. Conceivably, at these catecholamine concentrations, the blockade due to the competitive alpha and beta adrenergic receptor antagonists might have been overcome. It is also possible that hypoglycemia per se may decrease the effectiveness of competitive adrenergic antagonists. There is, however, no evidence to support this latter possibility. Regarding the former possibility, several observations suggest that the adrenergic antagonists were administered in sufficient amounts to provide continued blockade. First of all, we found that the effects of infusions of epinephrine and norepinephrine that produced circulating levels of these catecholamines similar to or greater than those observed during hypoglycemia were completely prevented by doses of adrenergic antagonists used during hypoglycemia. Second, during hypoglycemia, increases in plasma FFA were suppressed throughout the infusions of the adrenergic antagonists. Finally, there was no increase in heart rate during hypoglycemia under these conditions. These observations provide evidence that adrenergic blockade remained intact and suggest that it is unlikely that the increase in glucose production was due to release of neural norepinephrine or adrenomedullary catecholamines.

The mechanism by which glucose production becomes activated during hypoglycemia independent of neurohumoral influences is unclear. However, since plasma FFA concentrations were suppressed throughout our experiments and since Cori cycle and alanine cycle flux should have been decreased $(49,50)$, it seems unlikely that increases in availability of gluconeogenic precursors (glycerol, alanine, and lactate) or stimulatory effects of FFA on glucose production (51) were involved. Thus the results of the present study and the increases in glucose production observed during decreased media glucose concentrations with in vitro liver preparations $(4,6,9,13)$ suggest a direct intrahepatic mechanism. It is possible, for example, that reduced hepatic glucose flux could have deinhibited phosphorylase (1) and glucose-6-phosphatase (52) or decreased fructose-2,6 diphosphate (53). Such intrahepatic changes would promote glycogenolysis, gluconeogenesis, and release of glucose into the circulation $(1,52,53)$.

Although these studies indicate that hypoglycemia can activate hepatic glucose production independent of neurohumoral influences, this activation occurred only after plasma glucose concentrations had decreased below $50 \mathrm{mg} / \mathrm{dl}$ and glucose production increased only up to $60 \%$ of rates observed in control experiments $(\sim 1 \mathrm{mg} / \mathrm{kg}$ per $\mathrm{min})$. Thus, it can be concluded that hepatic autoregulation would ordinarily not be a major counterregulatory factor during moderate hypoglyce- mia. On the other hand, our results suggest that when other factors fail to prevent more severe hypoglycemia, activation of hepatic autoregulation may become important as an emergency system to prevent further decreases in plasma glucose concentrations and thus protect the brain from hypoglycemic damage.

Two lines of evidence support such a concept. Firstly, recent studies $(23,24)$ indicate that cerebral function begins to deteriorate in humans as plasma glucose concentrations decrease below $50 \mathrm{mg} / \mathrm{dl}$. In the present studies, when plasma glucose concentrations decreased below this level, activation of hepatic autoregulation began. Secondly, the human brain normally subsists almost exclusively on glucose and uses this substrate at a rate of $\sim 1 \mathrm{mg} / \mathrm{kg}$ per min (54). In the present studies, activation of hepatic autoregulation was sufficient to increase glucose production to this level. Thus, although hepatic autoregulation may not be as potent a factor in increasing glucose production during hypoglycemia as glucagon or catecholamines $(19,55)$, it appears to be sufficient in the face of physiologic hyperinsulinemia to increase glucose production enough to match cerebral glucose requirements. For these reasons, it seems plausible that hepatic autoregulation may act as an emergency system to reverse deteriorating cerebral function and to protect the brain from permanent damage when other counterregulatory factors have failed to prevent the development of threatening hypoglycemia. Indeed, hepatic autoregulation may be particularly important for patients with longstanding insulin-dependent diabetes in whom glucagon, epinephrine, and other counterregulatory hormone responses to hypoglycemia are frequently deficient (56-60).

In summary, these studies demonstrate that glucose counterregulation involves both neurohumoral and hepatic autoregulatory components: neurohumoral factors, which require only moderate hypoglycemia for their activation, augment glucose production and reduce glucose utilization; hepatic autoregulation requires severe hypoglycemia for its activation and thus may serve as a final emergency system to prevent hypoglycemic brain damage.

\section{Acknowledgments}

The superb editorial assistance of Pat Voelker is gratefully acknowledged. These studies were supported by the Italian National Research Council (Complications of Diabetes, Ob. 46), grant AM-20411 from the U. S. Public Health Service, and the Mayo Foundation.

\section{References}

1. Stalmans, W. 1976. The role of the liver in the homeostasis of blood glucose. Curr. Top. Cell. Regul. 11:51-97.

2. Soskin, S., H. Essex, J. Herrick, and F. Mann. 1938. The mechanism of regulation of the blood sugar by the liver. Am. J. Physiol. 124:558-567.

3. McCraw, E., M. Peterson, and J. Ashmore. 1967. Autoregulation of glucose metabolism in the isolated perfused rat liver. Proc. Soc. Exp. Biol. Med. 126:232-236.

4. Ruderman, N., and M. Herrera. 1968. Glucose regulation of hepatic gluconeogenesis. Am. J. Physiol. 214:1346-1351.

5. Glinsmann, W., E. Hern, and A. Lynch. 1969. Intrinsic regulation of glucose output by rat liver. Am. J. Physiol. 216:698-703.

6. Bucolo, R., R. Bergman, D. Marsh, and E. Yates. 1974. Dynamics of glucose autoregulation in the isolated blood perfused canine liver. Am. J. Physiol. 227:209-217.

7. Sacca, L., R. Henderler, and R. Sherwin. 1978. Hyperglycemia 
inhibits glucose production in man independent of changes in glucoregulatory hormones. J. Clin. Endocrinol. Metab. 47:1160-1163.

8. Liljenquist, J. E., G. Muller, A. D. Cherrington, J. Perry, and D. Rabinowitz. 1979. Hyperglycemia per se (insulin and glucagon withdrawn) can inhibit hepatic glucose production in man. J. Clin. Endocrinol. Metab. 48:171-175.

9. Davidson, M. 1981. Autoregulation by glucose of hepatic glucose balance: permissive effect of insulin. Metab. Clin. Exp. 30:279-284.

10. Gerich, J. E., R. A. Rizza, C. A. Verdonk, I. Gottesman, B. Baker, and G. Pehling. 1983. Effects of plasma glucose concentration on production, utilization and clearance of glucose in man. In Artificial Systems for Insulin Delivery. P. Brunetti, K. Alberti, A. Albisser, K. Hepp, and M. Bennedetti, editors. Raven Press, New York. 33-40.

11. Shulman, G. I., J. E. Liljenquist, P. E. Williams, W. W. Lacey, and A. D. Cherrington. 1978. Glucose disposal during insulinopenia in somatostatin-treated dogs. The roles of glucose and glucagon. J. Clin. Invest. 62:487-491.

12. Sokal, J., and B. Weintraub. 1966. Failure of the isolated liver to react to hypoglycemia. Am. J. Physiol. 210:63-68.

13. McCraw, E., and M. Peterson. 1967. Autoregulation of glucose metabolism in isolated perfused rat liver. Proc. Soc. Exp. Biol. Med. 126:232-236.

14. Koerker, D., and J. Halter. 1982. Glucoregulation during insulin and glucagon deficiency: role of catecholamines. Am. J. Physiol. 243:E225-E233.

15. Saccà, L., R. Sherwin, R. Hendler, and P. Felig. 1979. Influence of continuous physiologic hyperinsulinemia on glucose kinetics and counterregulatory hormones in normal and diabetic humans. J. Clin. Invest. 63:849-857.

16. Jarhult, J., B. Falck, S. Ingemansson, and A. Nobin. 1979. The functional importance of sympathetic nerves to the liver and endocrine pancreas. Ann. Surg. 189:96-100.

17. Cryer, P. E., and J. E. Gerich. 1983. Relevance of glucose counterregulatory systems to patients with diabetes: critical roles of glucagon and epinephrine. Diabetes Care. 6:95-99.

18. Gerich, J. E., J. Davis, M. Lorenzi, R. A. Rizza, J. Karam, S. Lewis, R. Kaplan, T. Schultz, and P. E. Cryer. 1979. Hormonal mechanisms of recovery from insulin-induced hypoglycemia in man. Am. J. Physiol. 236:380-385.

19. Rizza, R. A., P. E. Cryer, and J. E. Gerich. 1979. Role of glucagon, catecholamines, and growth hormone in human glucose counterregulation: effects of somatostatin and combined $\alpha$ - and $\beta$ adrenergic blockade on plasma glucose recovery and glucose flux rates after insulin-induced hypoglycemia. J. Clin. Invest. 64:62-71.

20. Bolli, G., P. De Feo, S. De Cosmo, G. Perriello, M. Ventura, P. Compagnucci, F. Santeusanio, J. E. Gerich, and P. Brunetti. 1984. A reliable and reproducible test for adequate glucose counterregulation in type I (insulin-dependent) diabetes mellitus. Diabetes. 33:732-737.

21. Verdonk, C. A., R. A. Rizza, R. L. Nelson, V. L. W. Go, J. E. Gerich, and F. J. Service. 1980. Interaction of fat-stimulated gastric inhibitory polypeptide on pancreatic alpha and beta cell function. J. Clin. Invest. 65:1119-1125.

22. Aver, R., Y. Olsson, and B. Siesjo. 1984. Hypoglycemic brain injury in the rat: Correlation of density of brain damage with EEG isoelectric time, a quantitative study. Diabetes. 33:1090-1098.

23. Cohen, R., K. Herold, J. Levy, D. Breed, F. Douglas, and K. Polonsky. 1984. Effects of hypoglycemia on cortical function in man. Diabetes. 33(Suppl. 1):17a.

24. Theilgaard, A., B. Thorsteinsson, E. Pinner, S. Pramming, and C. Binder. 1984. Neurophysiologic performance at different blood glucose concentrations in type I (insulin-dependent) diabetic patients. Diabetologia. 27:338a.

25. Silverberg, A., S. D. Shah, M. W. Haymond, and P. E. Cryer. 1978. Norepinephrine: hormone and neurotransmitter in man. Am. J. Physiol. 234:252-256.

26. Clutter, W. E., D. M. Bier, S. D. Shah, and P. E. Cryer. 1980.
Epinephrine plasma metabolic clearance rates and physiologic thresholds for metabolic and hemodynamic actions in man. J. Clin. Invest. 66: 94-101.

27. Herbert, V., L. Lau, C. Gottlieb, and S. Bleicher. 1965. Coated charcoal immunoassay of insulin. J. Clin. Endocrinol. Metab. 25: 1375-1384.

28. Faber, O., C. Binder, J. Markussen, L. Heding, V. Naithani, H. Kuzuya, P. Blix, D. Horwitz, and A. Rubenstein. 1978. Characterization of seven C-peptide antisera. Diabetes. 27(Suppl. 1):170-177.

29. Faloona, G., and R. Unger. 1974. Glucagon. In Methods of Hormone Radioimmunoassay. B. Jaffe and H. Behrman, editors. Academic Press, New York. 317-330.

30. Mattingly, D. 1964. A simple fluorimetric method for the estimation of 11-hydroxycorticoids in human plasma. J. Clin. Pathol. (Lond.). 15:374-379.

31. Peake, G. 1974. Growth hormone. In Methods of Hormone Radioimmunoassay. B. Jaffe and H. Behrman, editors. Academic Press, New York. 103-121.

32. Renzini, V., C. Brunori, and C. Valori. 1970. A sensitive and specific fluorimetric method for the determination of noradrenalin and adrenalin in human plasma. Clin. Chim. Acta. 30:587-594.

33. Dole, V., and H. Meinertz. 1960. Microdetermination of longchain fatty acids in plasma and tissues. J. Biol. Chem. 235:2595-2599.

34. De Bodo, R., R. Steele, N. Altszuler, A. Dunn, and J. Bishop. 1963. On the hormonal regulation of carbohydrate metabolism: studies with $C_{14}$ glucose. Recent Prog. Horm. Res. 19:445-488.

35. Rizza, R. A., L. Mandarino, and J. E. Gerich. 1981. Doseresponse characteristics for the effects of insulin on production and utilization of glucose in man. Am. J. Physiol. 240:E630-E639.

36. Sokal, R., and F. Rohlf. 1981. Biometry. W. H. Freeman \& Co. Publishers, New York. Second ed.

37. Iversen, L. 1975. Uptake processes for biogenic amines. In Handbook of Psychopharmacology, Vol. 3. L. Iversen, D. Iversen, and S. Snyder, editors. Plenum Publishing Corp., New York. 381-442.

38. Cryer, P. E., R. A. Rizza, M. W. Haymond, and J. E. Gerich. 1980. Epinephrine and norepinephrine are cleared through betaadrenergic but not alpha adrenergic mechanisms in man. Metab. Clin. Exp. 29(Suppl. 1):1114-1118.

39. Cryer, P. E. 1982. Hypoglycemic glucose counterregulation in patients with insulin dependent diabetes mellitus. J. Lab. Clin. Med. 99:451-456.

40. Gerich, J. E., P. E. Cryer, and R. A. Rizza. 1980. Hormonal mechanisms in actue glucose counterregulation: the relative roles of glucagon epinephrine, norepinephrine, growth hormone and cortisol. Metab. Clin. Exp. 29:1164-1175.

41. Rizza, R. A., L. Mandarino, and J. E. Gerich. 1982. Cortisolinduced insulin resistance in man: impaired suppression of glucose production and stimulation of glucose utilization due to a postreceptor defect in insulin action. J. Clin. Endocrinol. Metab. 54:131-138.

42. Shamoon, H., R. Hendler, and R. Sherwin. 1981. Synergistic interactions among antiinsulin hormones in the pathogenesis of stress hyperglycemia in humans. J. Clin. Endocrinol. Metab. 52:1235-1241.

43. Rizza, R. A., L. Mandarino, and J. E. Gerich. 1982. Effects of growth hormone on insulin action in man: mechanisms of insulin resistance, impaired suppression of glucose production and impaired stimulation of glucose utilization. Diabetes. 31:663-669.

44. Bratusch-Marrain, P., D. Smith, and R. DeFronzo. 1982. Effect of growth hormone on glucose metabolism and insulin secretion in man. J. Clin. Endocrinol. Metab. 55:973-982.

45. Rizza, R. A., P. E. Cryer, M. W. Haymond, and J. E. Gerich. 1980. Adrenergic mechanisms for the effects of epinephrine on glucose production and clearance in man. J. Clin. Invest. 65:682-689.

46. Saccà, L., G. Morrone, M. Cicala, G. Corso, and B. Ungaro. 1980. Influence of epinephrine, norepinephrine, and isoproterenol on glucose homeostasis in normal man. J. Clin. Endocrinol. Metab. 50: 680-684. 
47. Baxter, J., and P. Forsham. 1972. Tissue effects of glucocorticoids. Am. J. Physiol. 53:573-589.

48. MacGorman, L., R. A. Rizza, and J. E. Gerich. 1981. Physiologic concentrations of growth hormone exert insulin-like and insulin antagonistic effects on both hepatic and extrahepatic tissues in man. J. Clin. Endocrinol. Metab. 53:556-559.

49. Pozefsky, T., P. Felig, J. D. Tobin, J. S. Soeldner, and G. F. Cahill, Jr. 1969. Amino acid balance across tissues of the forearm in postabsorptive man: effects of insulin at two dose levels. J. Clin. Invest. 48:2273-2282.

50. Kreisberg, R. 1972. Glucose-lactate interrelations in man. N. Engl. J. Med. 287:132-137.

51. Williamson, J., R. Kreisberg, and P. Felts. 1966. Mechanism for the stimulation of gluconeogenesis by fatty acids in perfused rat liver. Proc. Natl. Acad. Sci. USA. 56:247-254.

52. Newgard, C., D. Foster, and J. McGarry. 1984. Evidence for suppression of hepatic glucose-6-phosphatase with carbohydrate feeding. Diabetes. 33:192-195.

53. Hers, H., and D. Van Schaftingen. 1982. Fructose 2,6-biphosphate 2 years after its discovery. Biochem. J. 206:1-12.

54. Huang, S., M. Phelps, E. Hoffman, K. Sideris, C. Selin, and D. Kuhl. 1980. Noninvasive determination of local cerebral metabolic rate of glucose in man. Am. J. Physiol. 238:E69-E82.
55. Popp, D. A., S. D. Shah, and P. E. Cryer. 1982. Role of epinephrine-mediated $\beta$-adrenergic mechanisms in hypoglycemic glucose counterregulation and posthypoglycemic hyperglycemia in insulindependent diabetes mellitus. J. Clin. Invest. 69:315-326.

56. Bolli, G., G. Dimitriadis, G. Pehling, B. Baker, M. W. Haymond, P. E. Cryer, and J. E. Gerich. 1984. Abnormal glucose counterregulation after subcutaneous insulin in insulin-dependent diabetes mellitus. N. Engl. J. Med. 310:1706-1711.

57. White, H., D. Skor, P. E. Cryer, L. Levandoski, D. M. Bier, and J. Santiago. 1983. Identification of type I diabetic patients at increased risk for hypoglycemia during intensive therapy. N. Engl. J. Med. 308:485-491.

58. Boden, G., G. Reichard, R. Hoeldtke, I. Rezvani, and O. Owen. 1981. Severe insulin-induced hypoglycemia associated with deficiencies in the release of counterregulatory hormones. N. Engl. J. Med. 305:1200-1205.

59. Polonsky, K., R. Bergenstal, G. Pons, M. Schneider, J. Jaspan, and A. Rubenstein. 1983. Relation of counterregulatory responses to hypoglycemia in type I diabetes. $N$. Engl. J. Med. 307:1106-1112.

60. Kleinbaum, J., and H. Shamoon. 1983. Impaired counterregulation of hypoglycemia in insulin-dependent diabetes mellitus. Diabetes. 32:493-498. 